\title{
The Navigation Wheel
}

\begin{abstract}
When people encounter moral dilemmas at work and have to decide on a course of action, they can respond intuitively or analytically. They can consider both utilitarian and duty ethics, as well as the principles of equality and publicity. This chapter introduces the Navigation Wheel, a tool that is designed to put ethics into a context that also includes the dimensions of law, identity, morality, reputation, and economy. The Navigation Wheel helps decision-makers to keep track of these six dimensions for each alternative. The relative priority of each dimension is open to discussion on a case-by-case basis.
\end{abstract}

Keywords Navigation Wheel $\bullet$ Ethical analysis $\bullet$ Facebook $\bullet$ Identity • Values

Moral dilemmas call for careful consideration and analysis. Ethics offer conceptual tools that can be used to engage in a systematic analysis of each course of action. The two main traditions of ethics emphasize conflicting aspects of a decision. Duty ethics focuses on respect and human dignity, whereas utilitarianism instructs the decision-maker to maximize utility and promote the common good-even when that requires using other people as means to that end. In addition, the principles of equality and publicity provide guidance for the evaluation of each alternative. These tools can be applied not just from the perspectives of duty ethics and utilitarianism but

(C) The Author(s) 2019

$\varnothing$. Kvalnes, Moral Reasoning at Work, https://doi.org/10.1007/978-3-030-15191-1_6 
also from a perspective that is (more or less) neutral with regard to the tension between those theories. In other words, a decision-maker can consider whether there is a morally relevant difference between two options without being committed to a particular ethical theory.

This chapter adds to the decision-maker's toolbox by introducing the Navigation Wheel, which I designed along with Einar Øverenget (Kvalnes \& Øverenget, 2012) as a new central component for organizational ethics training. The Navigation Wheel has been applied in ethics seminars and courses in a range of organizations in both the private and public sectors, as well as in organizations of various shapes and sizes. Its formative idea is to supply the participants with a simple tool that they can use in real-world settings in which they face moral dilemmas or other challenging decisions (see Fig. 6.1).

The set of questions presented in the Navigation Wheel belongs to a family of such analytic sets, from the simple ones such as: "Is it legal, is it fair, can I defend it?" (Blanchard \& Peale, 1988), or "Why is this bothering me?-Who else matters?-Is it my problem?-What is the ethical concern?-What do others think?-Am I being true to myself?" (Rion, 1990).

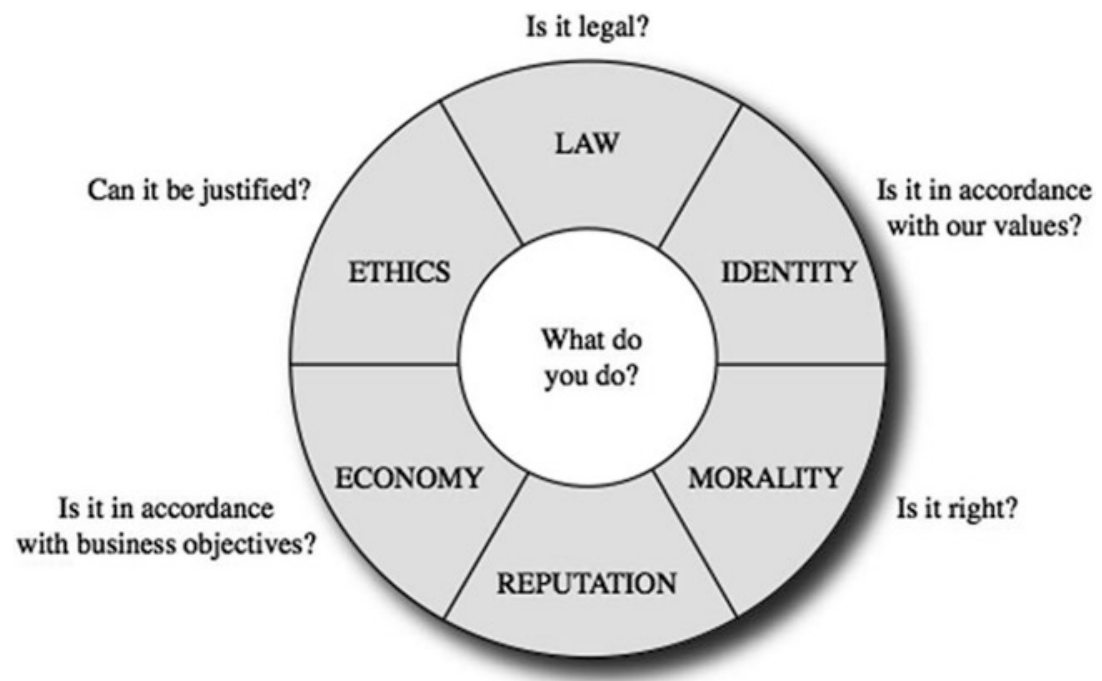

Does it affect our goodwill?

Fig. 6.1 The Navigation Wheel 
More complex approaches are described in van Luijk's 8-question list (2000), the 8-step list of Laczniak and Murphy (1985), the 12-step list of Nash (1981), and the 10-step list from the Markkula Center for Applied Ethics (Markkula, 2007).

The decision-maker can address the questions in the Navigation Wheel for each alternative, in no particular order. The proper weight of each item can vary based on the situation. Should ethical considerations trump economic ones in a particular case? Is morality more important than reputation in certain circumstances? What should one do if the choice is between going economically bankrupt and compromising one's values (and thus, one's identity)? The Navigation Wheel does not build on a particular theory of how to settle such issues. The tool's instructions do not indicate, then, that the decision-maker should apply a particular ranking or address these concerns in a particular order.

To illustrate the use of the Navigation Wheel, consider again Professor Claire and her decision regarding whether to keep the iPad that she got from her student.

\section{LAW: Is IT LEGAL?}

We can assume that both of Professor Claire's options are legal. She will not be committing an illegal act by keeping the iPad, but may be obliged to report the gift on her tax return as an asset gained through work. The alternatives of returning the iPad to the student or donating it to a charity, of course, are perfectly legal.

In general, for organizational decision-makers, the question of legality involves both national and international law. If an action is not legal, then a professional person has a strong reason to refrain from performing that action. A society's laws, however, may not be perfectly matched with the decision-maker's personal morality-and may even be at odds with the common morality of ordinary citizens in that society. Nevertheless, employees are bound by those laws and will normally owe their employers a certain respect for the boundaries of applicable national and international legal frameworks.

The term civil disobedience refers to behaviors that involve breaking the law for moral reasons. Even people who tend to be law-abiding citizens may use civil disobedience if they find the relevant moral considerations to be more important than the legal ones. Civil disobedience is normally restricted to one's actions as a private individual, rather than as 
an employee. Nevertheless, in some exceptional cases, it is reasonable to sympathize with a person who decides to break the law at work. Consider the following situation, in which the leader of a nursing home faced a dilemma (Kvalnes, 2017). On a hot summer's day, a local fisherman provided the leader with an offer of free fresh mackerel to serve for lunch at the home. The leader saw this as a chance to arrange a barbecue at which she could serve the residents excellent local fish, straight from the sea. However, the law on the matter is clear: The residents should only receive food from registered suppliers. Legal mackerel is controlled, processed, and packaged in a standard way, and it arrives on the residents' plates as gray and harmless matter. In this situation, the nursing-home leader could decide to take a chance and break the law, as the illegal fish will contribute to a far better culinary experience for the residents than the legal alternative. She could have staff members check the fish for bones and other harmful materials so as to make sure that it will be safe to serve it. This action would nevertheless be a risk; it would involve committing civil disobedience at work. The leader may also depend on moral luck, as the outcome of her decision will affect whether people see that decision as justifiable.

The case is discussed in further detail in Kvalnes (2017), in the context of fallibility, moral luck, and risk-taking in organizations. The purpose of relaying it here is to exemplify a situation in which civil disobedience can be a viable option for a decision-maker, even within a society that features a reasonably good match between morality and law.

The introduction of the Navigation Wheel (Kvalnes \& Øverenget, 2012) highlighted an interesting and important asymmetry with regard to legality. This asymmetry resides in the fact that the illegality of an action provides a reason to refrain from it, but the legality of an action does not provide a corresponding reason to act. Any person has access to plenty of legal actions that, for other reasons, are unwise. In other words, it is unconvincing to respond to the question "How could you do that?" by saying "Because it was legal."

Decision-makers should be aware of this asymmetry in the legal domain, but many fail to consider it. In a study of the causes of the financial crisis in Iceland, Salvör Nordal and I found that decision-makers in the financial industry justified their questionable behavior by claiming that they had not violated any laws (Kvalnes \& Nordal, 2018). That may have been true, but a behavior being legal is a poor justification for engaging in it. 


\section{Identity: Is It in Accordance with Our Values?}

Returning to Professor Claire's case, she could consider her options (keeping the iPad or returning it) in light of her organization's core values, as well as from a professional-values perspective. Perhaps her university has defined a set of core values to guide interactions both within the institution and between it and the outside world. Such values will typically include acting with respect, integrity, and openness. The latter value indicates that any decision she makes should pass the principle of publicity test (described in the previous chapter). She should be open about her decision and should not try to keep it a secret.

Professor Claire's decision may also be guided by the values she associates with being a professor, a researcher, and a supervisor of students. She received the gift in connection with her role as a supervisor, in which she is expected and required to be professional, acting with integrity and exhibiting dedication. Receiving a generous gift from a student at the end of a course may not, in itself, conflict with those values, but she should be prepared to explain her reasoning in light of these professional values.

This example illustrates how identity as it is defined in connection with the Navigation Wheel has two aspects, one connected to the core values of the decision-maker's organization and another connected to the core values of his or her profession. Since Collins and Porras (1996) documented that core values helped commercial organizations to flourish and remain stable, there has been a growing interest in the maintenance of identity in the organizational sense. Companies such as Sony, Disney, Volvo, and Nike have succeeded in staying loyal to their core values and thus have managed to establish easily recognizable identities that have benefitted them commercially.

The criticism of corporate misbehavior often involves pointing out a discrepancy between an organization's actions and its values. For instance, when Facebook encountered the 2018 scandal regarding its stewardship of user data, critics pointed to a conflict between the company's core value of openness and the ways in which the company secretly allowed third parties to access users' personal information (Granville, 2018). I revisit this example near the end of this chapter so as to illustrate how the Navigation Wheel can be used retrospectively, to analyze decisions and actions that have already been undertaken. 


\section{Morality: Is It Right?}

In line with the definition provided earlier in the book, morality has to do with both personal and shared beliefs about right and wrong. Individuals' moral convictions are more or less shared with the people in their communities. When moving from one culture to another, as from an Asian country to a European one, people thus may be struck by the differences between these places' established moralities. For instance, residents' beliefs about the line between gifts and bribes may differ; thus, the moral responses to Professor Claire's choice between keeping and returning the iPad will differ from culture to culture.

Convictions regarding when it is morally acceptable (or even required) to openly disagree with one's peers or leaders also vary from one society to another. In decision-making, both moral beliefs and convictions affect one's gut feelings-moral intuitions about the relative morality of the various alternatives. As such, morality affects System 1 (immediate and quick) decision-making (Kahneman, 2013).

\section{Reputation: Does It Affect Goodwill?}

When considering how a given decision will influence one's reputation, it is necessary to consider whether information about that decision will become openly available. If the decision-maker knows that the decision will remain a secret forever, then there is no reputational risk. If Professor Claire evaluated her choice strictly from a reputational perspective, she could assume that her goodwill would remain intact even if she kept the iPad, as she might plan to use it only at home and to not tell anyone about it. As noted earlier, the reputational consideration is different from the ethical consideration generated via the principle of publicity, in which one must consider whether to defend the decision publicly, regardless of the likelihood of such a scenario.

Professor Claire could be convinced that the student gave her the iPad to express gratitude rather than as an exchange for an improper advantage at a later date. She would be wise, however, to consider not only her perceptions of the case but also how the situation may appear to reasonable other individuals. Her reputation among her students could suffer significantly if they hear about the iPad; this gives her a good reason not to keep it. 
One of the main conclusions that Øverenget and I have drawn over many years of conducting ethics trainings with businesspeople is that they tend to be very concerned about their reputations (Kvalnes \& Øverenget, 2012). Businesspeople consider reputation to be necessary in reaching their strategic and economic goals. A commonly held view in business communities is that a good reputation takes years to build but can be lost very quickly.

Business leaders protect their reputation-even if that means admitting to wrongdoing when they have actually acted responsibly and wisely. The initial paper on this topic drew attention to the oil company Shell's maneuvers in the so-called Brent Spar case (Kvalnes \& Øverenget, 2012). When the company made plans to dispose of the Brent Spar oil-storage facility, which had become redundant, it consulted environment specialists. The specialists told Shell that the safest option, both environmentally and from the perspective of industrial health and security, was to dispose of the facility in deep Atlantic waters. British authorities accepted this plan as the best practicable environmental option (Zyglidopoulos, 2002). However, the activist group Greenpeace questioned the plan and started a campaign that led to a widespread boycott of Shell service stations in European countries. In response, Shell decided to abandon the plan for reputational and economic reasons. The company claimed that it needed to identify a better storage plan, even though its own studies had showed that deep-sea disposal off the coast Scotland was optimal from an environmental perspective. Later, Greenpeace had to publicly acknowledge that it had grossly overestimated the environmental damage that the proposed disposal of Brent Spar would cause. By that time, however, Greenpeace had won the fight with Shell, and the media was only mildly interested in the former's use of false numbers (Shell, 2008). Bowie and Dunfee (2002), in discussing such cases, questioned the wisdom of giving in to pressure so as to save reputation.

\section{Economy: Is It in AcCordance With Business OBJectives?}

This question can be relevant to decision-making involving individuals, groups, and organizations. When Professor Claire considered her options in the iPad case, economics were not the core concern, as none of the alternatives affected her economic standing in a significant way. 
Øverenget and I have found that the inclusion of economy in ethical analysis raises eyebrows. Why are business objectives addressed at all, when the focus is supposed to be on ethics? Monetary concerns and ethics seem to belong to different spheres, and many people argue that profitability should not be considered in organizational ethical training.

The standard reply to this position is that many of the most significant moral dilemmas in business involve the balancing of economic considerations with other dimensions. As noted earlier, a company can face a choice between economic and identity bankruptcy. For instance, say that a food manufacturer holds quality as a core value and has a history of delivering food that uses high-quality raw materials. When facing economic hardship, the company can opt to switch to low-quality raw materials so as to keep costs down and increase profits. By choosing that option, the company, in a significant sense, ceases to be what it was before. The company may keep the same name and address, but if it breaks with its core value, then a transformation takes place. In a significant way, its identity is lost.

\section{Ethics: Can It Be Justified?}

This question invites a consideration of the alternatives in light of the ethical theories and principles from the earlier chapters. The decision-maker can analyze the available options by applying the principles of equality and publicity. For instance, Professor Claire could analyze her choices after receiving the iPad in terms of these ethical principles. However, an even more thorough ethical analysis can be undertaken by applying the theoretical tools of utilitarianism and duty ethics. The former theory places the decision into the context of utility (for all those affected by the decision), and the latter focuses on honesty, dignity, and respect (regardless of outcome).

Once a decision-maker has considered all the questions from the Navigation Wheel for each alternative, that person is prepared to make a decision and act upon it. The main purpose of the Navigation Wheel is to assist in the decision-makers' efforts to analyze the available options and to keep track of the relevant dimensions. It can also be used retrospectively, to analyze and evaluate previous decision-making.

As an example, in 2018, Facebook faced criticism regarding its improper protection of sensitive user information. All six dimensions of the Navigation Wheel are relevant to evaluations of the company's behavior. Facebook had assisted the consultancy Cambridge Analytica in gaining 
access to the personal user data of several million Facebook users without those users' knowledge or consent (Granville, 2018). Cambridge Analytica was thus able to use the acquired data to help politicians focus their communications with the electorate. Cambridge Analytica gained access to these users' personal data by recruiting individuals to use an app called This Is Your Digital Life that involved completing a survey. The survey data was meant to only be used in academic research. Facebook's design allowed Cambridge Analytica to gain access to not just the personal information of the app's users but also that of all the people who were in those users' social networks. Cambridge Analytica then used that information to create psychographic profiles of millions of Facebook users. With that in place, the consultancy firm assisted politicians in targeting particular user groups with tailored messages. When the information about these processes became public, Facebook was heavily criticized for providing insufficient protection of its users' privacy, and CEO Mark Zuckerberg was forced to testify at a Senate hearing about the company's policies (Granville, 2018).

From a legal perspective, it is unlikely that Facebook committed a crime when it made the user data available to a third party. The Facebook users had all agreed, in the fine print of the site's terms of service, to share the users' personal data in this manner. However, this case has led to a tightening of privacy laws, such as the General Data Protection Regulation that the European Union Parliament passed in 2018.

Regarding identity, Facebook has identified five core values (published on www.facebook.com) that are supposed to guide its employees' and leaders' decision-making:

- Focus on impact

- Move fast

- Be bold

- Be open

- Build social value

The collaboration with Cambridge Analytica appears to clash with Facebook's value of openness, as its users were not told about the sharing of their personal information until well after the fact. The relevance of the other four values is more difficult to assess. Sharing personal data with a third party did have a significant impact; it most likely did come about through fast decision-making; and it was a bold move. Nevertheless, this 
is likely not what Facebook's leaders had in mind when they introduced these core values.

A consideration of Facebook's moral behavior should focus on the shared moral convictions and beliefs that its actions activate in people. What are people's gut feelings when they learn about the privacy issues related to Facebook's interactions with Cambridge Analytica? Because Facebook is a global company, with more than two billion users across various countries and cultures, the answers will differ. At my business school, I asked young ( 20 to 25 years old) students from various countries about the case, and many of them were considerably less morally aggrieved than the politicians and experts who dominate the public debate on the topic. The students' stance is that a social media platform cannot actually be used for free. Users pay by providing their personal data; this may be hidden in the fine print and come as a surprise to inexperienced users, but it is rather obvious to those who have grown up in the digital realm.

Facebook's reputation took a hit after the Cambridge Analytica revelations but was quickly restored. Vocal initiatives to get people to boycott the company (\#deletefacebook) eventually faded away without causing a dramatic impact on the site's core users. Users' loyalty and deeply ingrained habits appear to have helped the company through the crisis.

In terms of economy, Facebook's business model is based on earning money by profiling its users. Critical public scrutiny of privacy issues threatens that model. It remains to be seen how Facebook and other social media platforms will cope with this pressure to protect personal information. The question is whether companies can be reliable stewards of personal user data while simultaneously profiting from that information.

Finally, consider Facebook's involvement in the Cambridge Analytica scandal through the ethical lens by applying the principles of equality and publicity and viewing the situation from the utilitarian and deontological perspectives. When I have presented this case on exams, I have found that some students misunderstand utilitarian ethics. They think that utility applies only to stakeholders in the narrow sense, so they focus on the positives and negatives of the situation only for Facebook's owners, leaders, and employees. Utilitarian ethics, however, considers utility and impact for all stakeholders, so a proper utilitarian analysis should include the outcomes for society as a whole, rather than just the people who stand to gain or lose from a business perspective. If Facebook contributed to a weakening of democratic processes by making it possible to manipulate voting behavior, then utilitarian ethics would view that act negatively. 
The most significant application of duty ethics to the Facebook case evokes the humanity formulation of Immanuel Kant's categorical imperative, which states that it is morally wrong to use others (in this case, Facebook users) as means only to achieve one's goals (in this case, Facebook profits).

This chapter discussed how the Navigation Wheel can serve as an instrument to analyze dilemmas and other decision-making situations. This tool's prime function is to guide decision-makers toward a systematic evaluation of the alternatives, in preparation for a decision. This chapter also included the observation that the Navigation Wheel can be applied in a context such as that of Facebook's privacy scandal, so as to evaluate the various aspects of decision-making that have taken place.

The goal of the Navigation Wheel (and its accompanying training sessions) is to prepare people to cope with moral dilemmas at work. The question is whether these people are less likely to engage in serious moral wrongdoing after learning to use the Navigation Wheel. There are limitations to what can be achieved simply by familiarizing people with the tools of ethical analysis. Chapters 12 and 13 in this book will highlight how decision-making is also affected by circumstances, to the extent that even people with high personal moral standards and excellent ability to perform ethical analysis are vulnerable to becoming involved in moral misbehavior at work.

\section{REFERENCES}

Blanchard, K., \& Peale, N. V. (1988). The power of ethical management. New York: William Morrow and Company Inc.

Bowie, N. E., \& Dunfee, T. W. (2002). Confronting morality in markets. Journal of Business Ethics, 38(4), 381-393.

Collins, J. C., \& Porras, J. I. (1996). Building your company's vision. Harvard Business Review, 74(5), 65.

Granville, K. (2018). Facebook and Cambridge Analytica: What you need to know as fallout widens. The New York Times, 19.03.18.

Kahneman, D. (2013). Thinking, fast and slow. New York: Farrar, Straus and Giroux.

Kvalnes, Ø. (2017). Fallibility at work: Rethinking excellence and error in organizations. London: Palgrave Macmillan.

Kvalnes, Ø., \& Nordal, S. (2018). Normalization of questionable behavior: An ethical root of the financial crisis in Iceland. Journal of Business Ethics, 1-15. 
Kvalnes, Ø., \& Øverenget, E. (2012). Ethical navigation in leadership training. Etikk i praksis-Nordic Journal of Applied Ethics, 6(1), 58-71.

Laczniak, G. R., \& Murphy, P. E. (1985). Marketing ethics: Guidelines for managers. Lexington, MA: Lexington Books.

Markkula. (2007). A framework for thinking ethically from Markkula Center for Applied Ethics. Retrieved from https://www.scu.edu/ethics/ethics-resources / ethical-decision-making/a-framework-for-ethical-decision-making/

Nash, L. L. (1981). Ethics without the sermon. Harvard Business Review, 59(6), 79-90.

Rion, M. (1990). The responsible manager. San Francisco: Harper \& Row.

Shell. (2008). The Brent Spar dossier. Retrieved from www.shell.co.uk

van Luijk, H. J. L. (2000). In search of instruments. Business and ethics halfway. In Business challenging business ethics: New instruments for coping with diversity in international business (pp. 3-8): Springer.

Zyglidopoulos, S. C. (2002). The social and environmental responsibilities of multinationals: Evidence from the Brent Spar case. Journal of Business Ethics, 36(12), 141-151.

Open Access This chapter is licensed under the terms of the Creative Commons Attribution 4.0 International License (http://creativecommons.org/licenses/ by $/ 4.0 /$ ), which permits use, sharing, adaptation, distribution and reproduction in any medium or format, as long as you give appropriate credit to the original author(s) and the source, provide a link to the Creative Commons licence and indicate if changes were made.

The images or other third party material in this chapter are included in the chapter's Creative Commons licence, unless indicated otherwise in a credit line to the material. If material is not included in the chapter's Creative Commons licence and your intended use is not permitted by statutory regulation or exceeds the permitted use, you will need to obtain permission directly from the copyright holder.

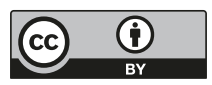

